\title{
An Examination of Moderators of Perceived Stress and Illness Behavior
}

\author{
Jenifer J. Thomas ${ }^{1}$, Evelinn A. Borrayo ${ }^{2}$ \\ ${ }^{1}$ Fay W. Whitney School of Nursing, University of Wyoming, Laramie, WY, USA; \\ ${ }^{2}$ Department of Psychology, University of Colorado-Denver, Denver, CO, USA. \\ Email: jthoma41@uwyo.edu \\ Received May $17^{\text {th }}, 2011$; revised July $1^{\text {st }}, 2011$; accepted August $14^{\text {th }}, 2011$.
}

\begin{abstract}
The purpose of this study was to examine multiple psychosocial factors (social support, negative affect, coping skills, and perceived health status) as moderators of perceived stress on illness behavior. College students recruited from undergraduate psychology courses completed measures in an on-line survey. Hierarchical multiple regression analyses indicated that commonly investigated psychosocial factors such as affectivity, coping, and social support moderated the relationship between perceived stress and one illness behavior (report of illness without visits to the doctor). However, other moderator variables less investigated, such as perceived health status had a significant effect on both illness behaviors (self-reported incidents of illness with and without visits to the doctor). Our findings highlight the role of behavioral health in primary care and the importance of educating individuals on the relationship between psychosocial factors and health.
\end{abstract}

Keywords: Illness Behavior, Psychosocial Factors, Patient Education

\section{Introduction}

The Transactional Model of Stress, proposed by Lazarus and Folkman (1984), emphasizes the relationship between environmental, psychological, and physiological processes; and research has identified psychosocial factors (processes pertaining to the interaction between social and psychological factors) that influence the experience of stress. For example, individuals who perceive high levels of social support feel less stress (Fleming, Baum, Gisriel, \& Gatchel, 1982; Stok, Harvey, \& Reddihough, 2006) and individuals who use approach type (proactive) coping styles tend to experience fewer psychological symptoms of stress (Dolbier, Smith, \& Steinhardt, 2007; Moos \& Schaefer, 1993). The impact of stress on illness has been found to vary based on the presence of certain psychosocial factors as well, including social support, emotional states, and coping skills (Cohen, Kessler, \& Gordon, 1995; Cohen \& Wills, 1985; Moos \& Schaefer, 1993). Recent research has focused on examining the impact of stress on the experience of specific illnesses or diseases via psychosocial factors (e.g., Devins, Bezjak, Mah, Loblaw, \& Gotoweic, 2006; Gerber \& Puhse, 2008).

\section{Illness Behavior}

Although various studies have investigated the moderating role of psychosocial factors in the stress-illness relationship, the effect of these moderators on behaviors associated with illness remains largely unexamined. Illness behaviors, such as those examined in the present study, include the activities an individual engages in to understand physical symptoms and to seek care to alleviate them (Herbert \& Cohen, 1994). Illness behaviors occur even when an objective measure (i.e., physical examination) has not confirmed the presence or absence of an organic condition. In other words, illness behavior refers to the varying ways in which individuals interpret and respond to their body sensations and internal states, define and interpret symptoms, make attributions, and take action through informal and formal care (Mechanic, 1995; Risor, 2006).

To elaborate upon the definition of illness behavior, Mechanic (1978) described these processes at four different levels of investigation. The first level includes dispositional factors such as gender. The second level includes psychosocial factors such as social support (Pilisuk, Boylan, \& Acredolo, 1987), perceived health status (Miilunpalo, Vuori, Oja, Pasanen, \& Urponen, 1997), coping (Soderstrom, Dolbier, Leiferman, \& Steinhardt, 2000), and perceived stress (Miranda, Perez-Stable, Munoz, Hargreaves, \& Henke, 1991). The third level includes the process of attribution and decision making such as attention and learning (Pennebaker, 2000) and perceived severity of the symptoms (Bury, 2005). The fourth level includes the structure of the health delivery system and the interactions between the individual and the health care system. Although these levels contain several important facets of illness behavior, Mechanic (1978) did not specifically define the interplay among the different levels (Risor, 2006). To further this approach to illness behavior research, the current study will consider interactions among the second level (psychosocial factors of social support, perceived health status, coping, and perceived stress) of investigation.

\section{Psychosocial Factors and Illness Behavior}

Research has explored a range of psychological and social factors that influence illness behavior. For example, high perceived stress levels have been found to be related to high numbers of medical visits (Miranda et al., 1991; Pilisuk et al., 1987) and increases in reported symptoms of illness (Mizco, Mizco, \& Johnson, 2006). High levels of social support are associated with lower medical utilization rates (Pilisuk et al., 1987), and patients with a negative perception of their heart disease symptoms report receiving less social support (Benyamini, Medalion, $\&$ Garfinkel, 2006). It has been found that negative affectivity is correlated with reported health complaints and upper respiratory infection (Cohen et al., 1995; Watson, Clark, \& Tellegen, 1988). The inability to adapt to or cope with difficult life cir- 
cumstances can intensify the experience of physical symptoms and poor health outcomes (Connor-Smith \& Compas, 2004; Soderstrom et al., 2000). Subjective perception of poor health has been found to be a strong predictor of increased physician visits (Miilunpalo et al., 1997).

Investigative approaches to illness behavior consider the independent influence of psychosocial factors, but the possibility of interactions among them is explored less often. Specifically, social support, affectivity, and coping may moderate the relationship between stress and illness behavior due to their influence on the experience of stress. That is, these psychosocial factors may intensify the relationship. The behaviors associated with the recognition and interpretation of symptoms, or illness behaviors, can be affected by individuals' vulnerability to stress (Costa \& McCrae, 1985). For example, in a sample of individuals with somatoform disorder it was found that psychological/stress factors were reported as highly relevant causes of bodily symptoms (Hiller et al., 2010). The degree of social support an individual receives is an important factor in the response to stress as individuals who perceive high levels of social support feel less stress (Fleming et al., 1982; Wilks \& Croom, 2008). Negative affectivity is also strongly correlated with reported stress symptoms (Klainin, 2009; Watson et al., 1988). In general, individuals who use approach coping styles tend to adapt better to life stressors and experience fewer psychological symptoms (Dolbier et al., 2007; Moos \& Schaefer, 1993). Therefore, psychosocial factors that influence individual appraisals and perceptions of abilities to cope with stress could potentially affect the relationship between stress and illness behavior

Individual perceptions of health may also moderate the relationship between stress and illness behavior, although literature on such a relationship is limited. Personal views of health and illness such as attitudes, perceptions, and emotions (including stress and anxiety) can affect awareness of physical symptoms and care seeking. For example, physically healthy individuals with high levels of emotional distress may view themselves as physically ill (Olfson, Gilbert, Weissman, Blacklow, \& Broadhead, 1995); this perception has also been found to be associated with increased use of physician services (Miilunpalo et al., 1997). In addition, negative changes in self-reported health were found to be frequently associated with stress and tension in a sample of caregivers (Byers, Beard, \& Wicks, 2009). Cognitive-perceptual factors (such as perceived health status and health self-efficacy) have been found to influence the maintenance of health-promoting behaviors, including seeking health care services when illness' symptoms are suspected (Jackson, Tucker, \& Herman, 2007).

Understanding how stress and other factors influence illness behaviors is important because it could aid in an understanding of how and under what circumstances individuals evaluate their health status and consequently use health services. In addition, such an examination could lead to health education that can more effectively motivate individuals to seek proper and timely health care/treatment. The purpose of this study was to examine multiple psychosocial factors (social support, negative affect, coping skills, and perceived health status) as moderators of perceived stress on illness behaviors in a sample of college students. The two illness behaviors considered were the self-report of number of visits to a health care provider and number of instances of illness without visits to a health care provider. It was hypothesized that less satisfaction with social support, high negative affectivity, use of more avoidant coping strategies, and poor perceived health status would intensify the effect of high perceived stress on high numbers of self-reported illness behaviors during the past six months.

\section{Method}

\section{Participants}

Sociodemographic information and complete surveys were obtained from a sample of 303 college students. The respondents were on average 19 years old (range 17-33 years), mostly female $(70 \%$ female), single ( $92 \%$ single), and Caucasian $(89 \%$ Caucasian/white). Academically, respondents had on average 14 credits, were mostly freshman (51\% freshman vs. $19 \%$ sophomore, $17 \%$ senior, and $12 \%$ junior), and most reported a cumulative grade point average of $2.6-3.0(26 \%)$. The employment status of respondents was $56 \%$ not working and $43 \%$ working. Most respondents lived on campus (52\%). With regard to healthcare services, $55 \%$ reported utilizing the University Health Services only, 22\% reported utilizing both the University Health Services and off campus health services and 21\% reported utilizing off campus health services only.

\section{Procedures}

Approval for this study was obtained from an Institutional Review Board. Students were recruited from a research pool and from undergraduate psychology courses at an accredited university, and self-selected into this study. Participants read and signed a consent form in-person and the surveys were administered on-line through the Student Voice survey package utilized by the university. They could complete the survey at any time during the last week of the fall semester. The entire survey took approximately between 30-60 minutes to complete. There were three versions of the survey (A, B, and C) with different ordering of the questionnaires within the survey to control for order effects.

\section{Measures}

Illness behavior. Participants reported on both (a) the number of instances of illness with a visit to a doctor in the past six months, and (b) the number of instances of illness without a visit to a doctor in the past six months.

Psychological stress. The Perceived Stress Scale (PSS) was used to measure levels of perceived stress over the past month (Cohen, Kamarck, \& Mermelstein, 1983). This 14-item measures levels of perceived stress and the degree to which respondents find their lives unpredictable, uncontrollable, and overloading. On a 5-point scale, ranging from never to very often, respondents were asked to report how often they perceived to feel stressed. Research has shown that it is a reliable and valid measure of self-reported stress (Cohen, Tyrrell, \& Smith, 1993). The alpha reliability for this scale in the current sample was 0.87 .

Social support. Social support was measured by the Social Support Questionnaire Short Form (SSQSR) (Sarason, Sarason, Shearin, \& Pierce, 1987). First, individuals were asked to list up to nine available others that they feel they can turn to in times of need (number score). Second, individuals were asked to rate degree of satisfaction with the perceived support from these sources on a 6-point Likert scale from "very satisfied" to "very dissatisfied" (dissatisfaction score) on six items that describe a variety of situations. The dissatisfaction score was used in this study due to large variability and outliers in the number score. The SSQSR has shown to be a reliable and valid measure 
of social support (Brown \& Schutte, 2006). The alpha reliability for this scale in the current sample was 0.80 .

Affect. Positive and negative affect was measured using the Positive affect and Negative affect scales, or PANAS (Watson et al., 1988). The PANAS estimates the degree of positive or negative affect and consists of 10 adjectives for Negative affect and 10 adjectives for Positive affect. Individuals were asked to rate on a 5-point scale the extent to which they have experienced each mood state. Empirical evidence supports that it is a reliable and valid measure of positive and negative affect (Bood, Archer, \& Norlander, 2004). The alpha reliability for this scale in the current sample was 0.85 .

Coping. Strategies to cope with stress were measured by the Brief COPE inventory (Carver, 1997). Individuals were asked to rate 28 items on a 4-point scale of what they generally do and feel when experiencing stressful events. The dimensionality of the 28 items was analyzed using maximum likelihood factor analysis in order to simplify the use of this scale in the statistical analysis. The rotated solution yielded two interpretable factors. Factor 1, or approach coping styles, accounted for $15.9 \%$ of the item variance, and factor 2 , or avoidant coping styles, accounted for $13.7 \%$ of the item variance. The total ratings on factor 2 became the avoidant coping score. The Brief COPE inventory has been found to be a reliable and valid measure of coping strategies (Norlander, Von Schedvin, \& Archer, 2005). The alpha reliability for this scale in the current sample was 0.79 .

Perceived health status and health history. A measure of perceived health status asked participants to rate their overall health at the present time as either: excellent, very good, good, fair, poor, or very poor. The use of this single item has been shown to be a valid measure of health status (Bowling, 2005). As part of the questionnaires, participants were asked to provide a history of past and current medical conditions, medication use, negative health behaviors (e.g., smoking, alcohol use), and positive health behaviors (e.g., regular exercise). These were measured as yes/no dichotomous variables.

\section{Data Analysis}

The Statistical Package for the Social Sciences (SPSS) was used for the data analysis. A hierarchical multiple regression model was used to analyze the collective and separate effects of perceived stress, negative affect, avoidant coping strategies, social support dissatisfaction, and perceived health status on two self-report instances of illness behaviors during the past six months: number of instances of illness with visits to a doctor and number of instances of illness without visits to a doctor (dependent measures).

For the two dependent measure equations, the covariates (sociodemographic predisposing characteristics that may confound the relationship between the independent and dependent variables) of age, living situation, university status, and cumulative grade point average were entered first. In preliminary analysis, these variables were highly correlated with independent and dependent variables. Entered second were the health status variables (predisposing health related variables that may influence stress and health outcomes), current medical conditions, past medical conditions, and current medication use. These variables were also highly correlated with independent and dependent variables in preliminary analysis. The main effects of perceived stress, negative affect, dissatisfaction with social support, avoidant coping strategies, and perceived health status were entered third. For the final step, interactions were entered into the regression equation as the product of two variables. Separate interaction variables were created based on perceived stress as the predictor and dissatisfaction with social support, negative affect, avoidant coping strategies, and perceived health status as moderators. Only significant interactions were preserved in the final analysis.

A power estimate was conducted for each of the dependent variables (DV) tested with an interaction to determine the adequacy of the explained variance detected with the number of participants that entered in the analysis for each DV (Cohen, 1988). For the self-reported visits to the doctor DV, at an alpha level of .05, the sample size of 265 participants yielded a power of approximately .90 to detect an effect that accounts for $17 \%$ of the variance. For the self-reported instances of illness without a visit to the doctor DV, at an alpha level of .05, the sample size of 274 participants yielded a power of .90 to detect an effect that accounts for $28 \%$ of the variance. According to this estimate, the number of participants that entered in the analysis of each DV allowed for medium (.60) to high (.90) power to detect effects that accounted for an adequate portion of the explained variance for each variable.

\section{Results}

Instances of illness with a visit to the doctor in the past six months ranged from 0 to $79(M=3.35$, median $=1.0, S D=$ 7.07). The higher mean reflects a skewed distribution, with a large number of fewer instances of illness behavior. As shown in Table 1, the presence of current medical conditions was a significant predictor. All variables entered in the regression equation accounted for $17 \%$ of the variance; $F(18,264)=2.83$, $p=.00$. The moderator analysis revealed one significant interaction. With excellent, very good, and fair perceived health status, as perceived stress increases there is minor change in incidents of self-reported visits to the doctor. However, with poor perceived health status, as perceived stress increases incidents of self-reported visits to the doctor decreases. Thus, the hypothesis that poor perceived health status would intensify the effect of high perceived stress on self-reported visits to the doctor was not supported. About $20 \%$ of the variance was accounted for when the moderators included in the equation; $F(19$, 264) $=3.22, p=0.00$.

Instances of illness without a visit to the doctor in the past six months ranged from 0 to $79(M=2.96$, median $=2.0, S D=$ 5.97). The higher mean reflects a skewed distribution, with a large number of fewer instances of illness behavior. As shown in Table 2, the presence of current medical conditions, major illnesses in the past, and perceived stress were significant predictors. This supported the hypothesis that self-reported incidents of illness without visits to the doctor would depend on high perceived stress. All variables entered in the regression equation accounted for $18 \%$ of the variance; $F(18,273)=3.18$, $p=.00$. The moderator analysis revealed four significant interactions. The first interaction revealed that with average and low levels of social support dissatisfaction, as perceived stress increases incidents of self-reported illness without a doctor visit increases. With high levels of social support dissatisfaction, as perceived stress increases incidents of self-reported illness without a doctor visit decreases. The next interaction shows that with high and average levels of negative affectivity, as perceived stress increases incidents of self-reported illness without a doctor visit increases. With low levels of negative affectivity, increases in perceived stress corresponded with decreases in 
Table 1.

Hierarchical regression prediction of self-reported instances of illness with visits to the doctor in the past six months.

\begin{tabular}{|c|c|c|c|}
\hline & Variables & $B$ & $t$ \\
\hline \multirow[t]{4}{*}{ Step 1} & Age & -.04 & -.11 \\
\hline & Living situation & -.04 & -.29 \\
\hline & University status & .12 & .20 \\
\hline & Grade point average & -.01 & -1.22 \\
\hline \multirow[t]{3}{*}{ Step 2} & Current medical conditions & -2.55 & $-2.41^{*}$ \\
\hline & Major illnesses in the past & -.70 & -.73 \\
\hline & Current medication use & 1.89 & 1.94 \\
\hline \multirow[t]{10}{*}{ Step 3} & PSS (One month) & .08 & 1.00 \\
\hline & SSQ (Dissatisfaction) & .11 & .21 \\
\hline & $\begin{array}{l}\text { PANAS } \\
\text { (Negative affectivity) }\end{array}$ & -.03 & -.37 \\
\hline & $\begin{array}{l}\text { Brief COPE } \\
\text { (Avoidant coping) }\end{array}$ & -.04 & -.35 \\
\hline & $\begin{array}{l}\text { Perceived health status } \\
\text { (as compared to good) }\end{array}$ & & \\
\hline & Excellent & 1.60 & 1.36 \\
\hline & Very good & .25 & .21 \\
\hline & Fair & -.56 & -.40 \\
\hline & Poor & -18.19 & -1.87 \\
\hline & Very poor & -1.76 & -.26 \\
\hline Step 4 & $\begin{array}{l}\text { PSS * Poor Perceived } \\
\text { Health Status }\end{array}$ & 1.25 & $2.96^{* *}$ \\
\hline
\end{tabular}

Note: $(N=265)$. PSS $=$ Perceived Stress Scale. SSQ $=$ Social Support Questionnaire. PANAS $=$ Positive and Negative Affectivity Scales. $B$ and $t$ are shown from the last step with all variables entered. $\mathrm{R}^{2}=.01$ for Step $1 ; \mathrm{R}^{2}$ change $=.08$ for Step 2; $\mathrm{R}^{2}$ change $=.08$ for Step $3 ; \mathrm{R}^{2}$ change $=.03$ for Step 4 . Total $\mathrm{R}^{2}=.20$ at the last step. ${ }^{*} p<.05, * * p<.01$.

incidents of self-reported illness without a doctor visit. The third interaction also revealed that with high and average levels of avoidant coping, as perceived stress increases incidents of self-reported illness without a doctor visit increases. When low levels of avoidant coping are reported, as perceived stress increases incidents of self-reported illness without a doctor visit decreases. The final interaction revealed that with excellent, very good, and poor perceived health status (as compared to good), as perceived stress increases incidents of self-reported illness without a doctor visit increases. With fair perceived health status, as perceived stress increases incidents of selfreported illness without a doctor visit decreases. These findings supported the hypotheses that high negative affectivity, more avoidant coping strategies, and poor perceived health status would intensify the effect of high perceived stress on high self-reported illness without visits to the doctor in the past six months. However, our findings did not support the hypothesis that less satisfaction with social support would intensify the effect of high perceived stress on increased number of selfreported illnesses without visits to the doctor. When the moderators were included in the equation, $30 \%$ of the variance was accounted for; $F(22,273)=4.97, p=0.00$.
Table 2.

Hierarchical regression prediction of self-reported instances of illness without visits to the doctor in the past six months.

\begin{tabular}{|c|c|c|c|}
\hline & Variables & $B$ & $t$ \\
\hline \multirow[t]{4}{*}{ Step 1} & Age & .18 & .61 \\
\hline & Living situation & -.00 & -.01 \\
\hline & University status & -.81 & -1.69 \\
\hline & Grade point average & -.01 & -.59 \\
\hline \multirow[t]{3}{*}{ Step 2} & Current medical conditions & -2.53 & $-3.05^{* *}$ \\
\hline & Major illnesses in the past & 1.49 & $1.20^{*}$ \\
\hline & Current medication use & 1.34 & 1.76 \\
\hline \multirow[t]{10}{*}{ Step 3} & PSS (One month) & .14 & $2.07 *$ \\
\hline & SSQ (Dissatisfaction) & -.21 & -.47 \\
\hline & $\begin{array}{l}\text { PANAS } \\
\text { (Negative affectivity) }\end{array}$ & .01 & .07 \\
\hline & $\begin{array}{l}\text { Brief COPE } \\
\text { (Avoidant coping) }\end{array}$ & .00 & .98 \\
\hline & $\begin{array}{l}\text { Perceived health status } \\
\text { (as compared to good) }\end{array}$ & & \\
\hline & Excellent & -.68 & -.74 \\
\hline & Very good & -.48 & -.53 \\
\hline & Fair & 4.54 & 1.49 \\
\hline & Poor & 3.00 & 1.65 \\
\hline & Very poor & -8.10 & -1.48 \\
\hline \multirow[t]{4}{*}{ Step 4} & $\begin{array}{l}\text { PSS * SSQ } \\
\text { (Dissatisfaction) }\end{array}$ & -.20 & $-3.49 * *$ \\
\hline & $\begin{array}{l}\text { PSS * PANAS } \\
\text { (Negative affectivity) }\end{array}$ & .02 & $2.78^{* *}$ \\
\hline & $\begin{array}{l}\text { PSS * Brief COPE } \\
\text { (Avoidant coping) }\end{array}$ & .04 & $4.05^{* *}$ \\
\hline & $\begin{array}{l}\text { PSS * Fair Perceived } \\
\text { Health Status }\end{array}$ & -.39 & $-2.69^{* *}$ \\
\hline
\end{tabular}

Note: $(N=274)$. PSS $=$ Perceived Stress Scale. $S S Q=$ Social Support Questionnaire. PANAS $=$ Positive and Negative Affectivity Scales. $B$ and $t$ are shown from the last step with all variables entered. $\mathrm{R}^{2}=.02$ for Step $1 ; \mathrm{R}^{2}$ change $=.06$ for Step $2 ; \mathrm{R}^{2}$ change $=.10$ for Step $3 ; \mathrm{R}^{2}$ change $=.12$ for Step 4 . Total $\mathrm{R}^{2}=.30$ at the last step. ${ }^{*} p<.05, * * p<.01$.

\section{Discussion}

This study contributes to the limited literature that has examined the psychosocial factors that moderate the relationship between perceived stress and illness behavior. While psychosocial factors have previously and consistently been found to have an effect on the stress-illness relationship, those examined in this study demonstrate a particular moderating effect on behavior. More specifically, the study findings demonstrate that commonly investigated psychosocial factors such as affectivity, coping, and social support moderated the relationship between perceived stress and one illness behavior (report of illness without visits to the doctor). However, other moderator variables less investigated, such as perceived health status had a significant effect on both illness behaviors (self-reported inci- 
dents of illness with and without visits to the doctor). The current investigation of multiple moderators and more than one health outcome measure provides a broader picture of the moderating effect of psychosocial factors on behavior.

The results regarding social support found that participants with more illness behaviors, and more specifically those who reported feeling ill without visiting the doctor, were more satisfied with social support. These findings were inconsistent with the hypothesized relationship and with studies that have found social support satisfaction as a buffer for the effects of stress on health (Cropley \& Steptoe, 2005; Treharne, Lyons, \& Tupling, 2001). However, other studies have found no correlation between stress and social support (Dwyer \& Cummings, 2001) or between positive social support and physical symptoms (Edwards, Hershberger, Russell, \& Markert, 2001). Zaleski, Levey-Thors, and Schiaffino (1998) found that college students with high family social support reported more physical symptoms when faced with stress, possibly due to separation from the main source of social support. The inconsistency in the current study could be due to the measurement of social support. First, it is often unclear what providers of social support do to encourage or influence health-related behavior, including illness behavior (Thoits, 2001). In the current study, it is possible that individuals who were stressed and felt ill had adequate social support to handle the situation and were then less likely to go to the doctor. Second, a measure of overall satisfaction with social support was used and may have been too global to capture the specific way in which social support was operational for individuals. It is possible that specific types of social support (e.g., emotional, instrumental, informational, etc.) may have been associated to illness behavior in this sample. These results suggest that the impact of social support on health care seeking behaviors is more complex than one's report of satisfaction/dissatisfaction alone. Perhaps specific types of social support impact decisions to seek care or not depending on context (i.e., environment and access) and other skills (i.e., coping skills and resources). Health care providers and health educators should continue to inquire about and encourage social support when promoting healthy behaviors and self-care. Although it appears as though detailed inquiry of the type of social support is important to consider.

Results concerning negative affectivity found that participants with more illness behavior experienced more negative emotions. Negative affectivity has been found to be strongly correlated with reports of perceived stress and health complaints (Watson et al., 1988), as well as with reports of physical symptoms and illness (Mathis \& Lecci, 1999). These results suggest that because negative affectivity may aggravate the effects of stress on health it is an important factor to consider when creating interventions that target stress reduction and health improvement. For example, Klainin (2009) found a relationship between negative affectivity, work stress, family stress, and health outcomes in health care workers and suggests that interventions should include strategies that promote realistic and positive thinking. Although, it has been suggested that negative affect could potentially influence self-report measures of stress and health (Mathis \& Lecci, 1999; Watson \& Pennebaker, 1989) and negative affectivity is often controlled for in statistical analysis. In the current sample, it is possible that student recall of past incidents of illness behavior may have been biased by their current mental state as the data collection occurred during the week before finals. Among interactions between individuals and health care providers, recall of symptoms and behavior is an important part of communication about health status. Health care providers should consider that negative affectivity may impact reporting and should explore this with the individual. Providers should also consider that presenting an individual with strategies to impact overall negative affectivity (e.g., realistic thinking) may influence health concerns and behavior.

The results regarding coping were as expected in the current study. By in large, individuals with more illness behaviors, and more specifically those who reported feeling ill without visiting the doctor, implemented more avoidant coping strategies. Avoidant coping strategies have been found to be associated with stress, symptoms of illness, and poor health outcomes (Dyson \& Renk, 2006; Pritchard, Wilson, \& Yamnitz, 2007). These results imply that poor coping strategies may impact self-care and subsequent decisions related to health. Tanaka, Fukuda, Mizuno, Kuratsune, and Watanabe (2009) found that stress and avoidant coping styles were related to severe fatigue in medical students and suggest efforts to develop educational training programs that reduce stress and help guide individuals to develop efficient coping styles. Assessment of coping strategies continues to have an important relationship with stress reduction, but also with overall health.

Levels of perceived health status were found to have different influences on the relationship between perceived stress and each illness behavior (self-reported incidents of illness with and without visits to the doctor). First, excellent, very good, and fair perceived health status had minimal influence on the relationship between perceived stress and illness with visits to the doctor. On the other hand, individuals who were highly stressed and viewed their overall health status as poor were less likely to indicate that they felt ill and went to the doctor. This result did not support the expected association between perceived poor health status and increase in illness behaviors as others have found (e.g., Miilunpalo et al., 1997). Second, the moderation effect of perceived health status on perceived stress and incidents of illness without a doctor visit was also unexpected and complex. Individuals who were highly stressed and viewed their overall health as excellent, very good, and poor were more likely to indicate that they felt ill and did not go to the doctor. On the other hand, those with high stress and a view of fair health status were less likely to indicate that they felt ill and did not go to the doctor. These results suggest that the expected association between perceived health status and health care seeking behavior is complicated by the inclusion of perceived stress. Because perceived health status is affecting the perceived stress and illness behavior relationship in a way that has not been previously observed, this variable needs to be further investigated. It is possible that the perception of health status impacts the perception of stress, rather than the other way around.

\section{Limitations and Future Research}

Overall, the psychosocial factors examined in the current study had an impact on instances of illness without visits to the doctor and not on instances of illness with visits to the doctor. Although, conclusions based on this fact should be done with caution as it is probable that this outcome was measuring the two factors of symptoms (report of being ill) and behavior (report of decision to visit the doctor or not). The accuracy of self-report data, particularly of health behaviors, is at times questionable (Degnan et al., 1992). Among the most common is that individuals differ with regard to the meaning attributed to their experiences, such as those related to health center visits 
(Mathis \& Lecci, 1999) and to the labeling and perception of their symptoms (Herbert \& Cohen, 1994). In this study it is not clear what type of illness (i.e., cold, hangover) is related to the reported behavior. In addition, other factors that influence illness-related decisions were not measured (i.e., not seeking formal care due to over-the-counter medication use, lack of knowledge of campus health resources). The cross sectional nature of the data collection limits the extent to which the path of the relationships can be discerned with certainty. A moderation analysis was used to examine the strength of the relationship between variables but it is possible that some of the variables were more suitable for mediation. In addition, seeking other sources of corroborating information (i.e., health center records, symptom diary) might have provided supporting evidence to test the relationships of interest. The large sample size allows for adequate statistical power for linear relationships but such sample size may not have been adequate for moderation analysis (McClelland \& Judd, 1993). Although it is important to study non-experimental relationships between stress and illness behavior, it can be difficult to obtain large sample sizes to detect true relationships.

The results of this study are only appropriate to generalize to college and university students due to the unique aspects of college life. The sample was mostly first and second year students and the results may not apply to older and more experienced individuals. However, implications for the integration of mental health into primary care as well as the design of future interventions might be derived from this study's findings; specifically, to consider the impact of stress-related psychosocial factors on healthcare seeking behavior. In the patient-centered health home model of primary care, health care is coordinated amongst an interdisciplinary team and individuals have increased access to mental health care (DeAngelis, 2010). Based on the results of the current study, it would be important for individuals to be educated on the influence of avoidant coping styles and negative affectivity on health as they may intensify the effect of stress on illness behaviors. For example, when individuals present with numerous physical symptoms during medical visits healthcare providers could inquire about stress, coping skills, and affect. Referrals could then be made to behavioral health specialists or counselors for skill instruction and/or other behavioral interventions. In addition, when individuals reveal avoidant coping styles and/or negative affectivity during a medical visit, brief behavioral health interventions (i.e., cognitive-behavioral strate- gies such as positive thinking, cognitive restructuring) might help individuals to understand how these factors affect each other. Such interventions could improve coping and decrease negative affectivity under stressful circumstances, and therefore positively impact health. The evaluation of the outcomes of practice that integrate treatment for mental and physical health will provide further support for the role of behavioral health in primary care (DeAnglelis, 2010). Perceived stress and its effects on health are of growing concern for individuals living in fast-paced and socially demanding societies. Therefore, it is important to provide education on the role of psychosocial factors and to encourage individuals to use or modify behaviors in efforts to maintain good health and decrease unnecessary and costly illness behaviors (Hudd et al., 2000).

Research should continue to examine the impact of moderating factors on illness behavior specifically. The current study, through its research design, provides evidence that the use of multiple moderators and multiple health outcomes may provide a more complex picture of the how psychological factors influ- ence the stress and illness behavior relationship. Future research investigating the impact of psychosocial variables on the stress and illness behavior relationship should be as specific as possible on what aspects of the variables are being tested in order to discern the mechanisms through which their moderating effect operates. Future studies should also consider other health-related behavior outcomes (e.g., health information seeking, the use of home remedies) that may possibly be explained by the impact of certain psychosocial moderators. In addition, future research should explore the specific aspects of perceived health that moderate the relationship between stress and illness behaviors to clarify the current results. The measurement of illness behavior and health perception continues to be of importance as it provides information about how individuals' health is expressed and how it is affected by their perception and behavior.

\section{Conclusion}

Affectivity, coping, and social support moderated the relationship between perceived stress and one illness behavior (report of illness without visits to the doctor). However, perceived health status had a significant effect on both illness behaviors (self-reported incidents of illness with and without visits to the doctor). Perceived health status is less commonly studied as a potential moderator of illness behavior and further investigation is needed. Education on the role of psychosocial factors may empower individuals to decrease potentially unnecessary and costly illness behaviors.

\section{Acknowledgements}

The authors would like to thank the undergraduate research assistants at Colorado State University (CSU) who contributed to data collection, preparation, and entry. The authors would also like to express their gratitude to Charles Davidshofer, Tracy Nelson-Ceschin, and Richard Suinn for serving on the graduate committee for this project.

\section{References}

Benyamini, Y., Medalion, B. \& Garfinkel, D. (2006). Patient and spouse perceptions of the patient's heart disease and their associations with received and provided social support and undermining. Psychology and Health, 22, 765-785.

doi:10.1080/14768320601070639

Bood, S., Archer, T., \& Norlander, T. (2004). Affective personality in relation to general personality, self-reported stress, coping, and optimism. Individual Differences Research, 2, 26-37.

Bowling, A. (2005). Just one question: If one question works, why ask several? Journal of Epidemiology and Community Health, 59, 342345. doi: $10.1136 /$ jech.2004.021204

Brown, R., \& Schutte, N. (2006). Direct and indirect relationships between emotional intelligence and subjective fatigue in university students. Journal of Psychosomatic Research, 60, 585-593. doi:10.1016/j.jpsychores.2006.05.001

Bury, M. (2005). Health and illness: Short introductions. Massachusetts: Polity Press.

Byers, D., Beard, T., \& Wicks, M. (2009). African-American women's perceived health status while caring for a relative with end stage renal disease. Nephrology Nursing Journal, 36, 599-632.

Carver, C. (1997). You want to measure coping but your protocol's too long: Consider the brief COPE. International Journal of Behavioral Medicine, 4, 92-100.

Cohen, J. (1988). Statistical power analysis for the behavioral sciences. 
New Jersey: Lawrence Erlbaum Associates. doi:10.1207/s15327558ijbm0401 6

Cohen, S., Kamarck, T., \& Mermelstein, R. (1983). A global measure of perceived stress. Journal of Health and Social behavior, 24, 385396. doi: $10.2307 / 2136404$

Cohen, S., Kessler, R., \& Gordon, L. (1995). Strategies for measuring stress in studies of psychiatric and physical disorders. In S. Cohen, R. Kessler, \& L. Gordon (Eds.), Measuring Stress (pp. 3-26). New York, NY: Oxford University Press.

Cohen, S., Tyrrell, D., \& Smith, A. (1993). Negative life events, perceived stress, negative affect, and susceptibility to the common cold. Journal of Personality and Social Psychology, 64, 131-140. doi:10.1037/0022-3514.64.1.131

Cohen, S., \& Wills, T. (1985). Stress, social support, and the buffering hypothesis. Psychological Bulletin, 93, 310-357. doi:10.1037/0033-2909.98.2.310

Connor-Smith, J., \& Compas, B. (2004). Coping as a moderator of relations between reactivity to interpersonal stress, health status, and internalizing problems. Cognitive Therapy and Research, 28, 347368. doi:10.1023/B:COTR.0000031806.25021.d5

Costa, P., \& McCrae, R. (1985). Hypochondriasis, neuroticism, and aging. When are somatic complaints unfounded? American Psychologist, 40, 19-28. doi:10.1037/0003-066X.40.1.19

Cropley, M., \& Steptoe, A. (2005). Social support, life events and physical symptoms: A prospective study of chronic and recent life stress in men and women. Psychology, Health \& Medicine, 10, 317325. doi:10.1080/1354850500093365

DeAngelis, T. (2010). Placing the patient front and center. Monitor on Psychology, 41, 42-47.

Degnan, D., Harris, R., Ranney, J., Quade, D., Earp, J., \& Gonzales, J. (1992). Measuring the use of mammography: Two measures compared. American Journal of Public Health, 82, 1386-1388. doi:10.2105/AJPH.82.10.1386

Devins, G., Bezjak, A., Mah, K., Loblaw, A., \& Gotoweic, A. (2006). Context moderates illness induced lifestyle disruptions across life domains: A test of the illness intrusiveness theoretical framework in six common cancers. Psycho-Oncology, 15, 221-233. doi:10.1002/pon. 940

Dolbier, C., Smith, S., \& Steinhardt, M. (2007). Relationship of protective factors to stress and symptoms of illness. American Journal of Health Behavior, 31, 423-433.

Dwyer, A., \& Cummings, A. (2001). Stress, self-efficacy, social support, and coping strategies in university students. Canadian Journal of Counseling, 35, 208-220.

Dyson, R., \& Renk, K. (2006). Freshman adaptation to university life: Depressive symptoms, stress, and coping. Journal of Clinical Psychology, 62, 1231-1244. doi:10.1002/jclp.20295

Edwards, K., Hershberger, P., Russell, R., \& Markert, R. (2001). Stress, negative social exchange, and health symptoms in university students. Journal of American College Health, 50, 75-79. doi:10.1080/07448480109596010

Fleming, R., Baum, A., Gisriel, M., \& Gatchel, R. (1982). Mediating influences of social support on stress at Three Mile Island. Journal of Human Stress, 8, 14-22.

Gerber, M., \& Puhse, U. (2008). "Don't crack under pressure!” Do leisure time physical activity and self-esteem moderate the relationship between school-based stress and psychosomatic complaints? Journal of Psychosomatic Research, 65, 363-369. doi:10.1016/j.jpsychores.2008.06.012

Herbert, T., \& Cohen, S. (1994). Stress and illness. Encyclopedia of Human Behavior, 4, 325-332.

Hiller, W., Cebulla, M., Korn, H., Leibbrand, R., Roers, B., \& Nilges, P. (2010). Causal symptom attributions in somatoform disorder and chronic pain. Journal of Psychosomatic Research, 68, 9-19. doi:10.1016/j.jpsychores.2009.06.011

Hudd, S., Dumlao, J., Erdmann-Sager, D., Murray, D., Phan, E., Soukas, N., \& Yokozuka, N. (2000). Stress at college: Effects on health habits, health status and self-esteem. College Student Journal, 34, 217227.

Jackson, E., Tucker, C., \& Herman, K. (2007). Health value, perceived social support, and health self-efficacy as factors in a health-promoting lifestyle. Journal of American College Health, 56, 69-74. doi:10.3200/JACH.56.1.69-74
Klainin, P. (2009). Stress and health outcomes: The mediating role of negative affectivity in female health care workers. International Journal of Stress Management, 16, 45-64. doi:10.1037/a0013693

Lazarus, R., \& Folkman, S. (1984). Stress, appraisal, and coping. New York: Springer Publishing Company.

Mathis, M., \& Lecci, L. (1999). Hardiness and college adjustment: Identifying students in need of services. Journal of College Student Development, 40, 305-309.

McClelland, G., \& Judd, C. (1993). Statistical difficulties of detecting interactions and moderator effects. Psychological Bulletin, 114, 376390. doi:10.1037/0033-2909.114.2.376

Mechanic, D. (1978). Illness behavior. In D. Mechanic (Ed.), Medical sociology (pp. 249-289). The Free Press: New York.

Mechanic, D. (1995). Sociological dimensions of illness behavior. Social Science Medicine, 41, 1207-1216.

doi:10.1016/0277-9536(95)00025-3

Miranda, J., Perez-Stable, E., Munoz, R., Hargreaves, W., \& Henke, C. (1991). Somatization, psychiatric disorder, and stress in utilization of ambulatory medical services. Health Psychology, 10, 46-51. doi:10.1037/0278-6133.10.1.46

Miilunpalo, S., Vuori, I., Oja, P., Pasanen, M., \& Urponen, H. (1997). Self-rated health status as a health measure: The predictive value of self-reported health status on the use of physician services and on mortality in the working-age population. Journal of Clinical Epidemiology, 50, 517-528. doi:10.1016/S0895-4356(97)00045-0

Mizco, N, Mizco, L, \& Johnson, M. (2006). Parental support, perceived stress, and illness-related variables among first-year college students. The Journal of Family Communication, 6, 97-117. doi:10.1207/s15327698jfc0602_1

Moos, R., \& Schaefer, J. (1993). Coping resources and processes: Current concepts and measures. In L. Goldberger and S. Breznitz (Eds.), Handbook of Stress (2nd ed.), (pp. 127-141). New York: The Free Press.

Norlander, T., Von Schedvin, H., \& Archer, T. (2005). Thriving as a function of affective personality: Relation to personality factors, coping strategies, and stress. Anxiety, Stress, \& Coping, 18, 105-116. doi:10.1080/10615800500093777

Olfson, M., Gilbert, T., Weissman, M., Blacklow, R., \& Broadhead, W. (1995). Recognition of emotional distress in physically healthy primary care patients who perceive poor physical health. General Hospital Psychiatry, 17, 173-180. doi:10.1016/0163-8343(95)00023-K

Pennebaker, J. (2000). Psychological factors influencing the reporting of physical symptoms. In A. Stone, J. Turkkan, C. Bachrach, J. Jobe, H. Kurtzman, \& V. Cain (Eds.), The science of self-report: Implications for research and practice (pp. 299-315). New Jersey: Lawrence Erlbaum Associates.

Pilisuk, M., Boylan, R., \& Acredolo, C. (1987). Social support, life stress, and subsequent medical care utilization. Health Psychology, 6, 273-288. doi:10.1037/0278-6133.6.4.273

Pritchard, M., Wilson, G., \& Yamnitz, B. (2007). What predicts adjustment among college

students? A longitudinal panel study. Journal of American College Health, 56, 15-21. doi:10.3200/JACH.56.1.15-22

Risor, M. (2006). Illness behavior and functional somatic symptoms: Rethinking the concept of illness behavior from an anthropological perspective. Social Theory \& Health, 4, 180-201. doi:10.1057/palgrave.sth. 8700070

Sarason, I., Sarason, B., Shearin, E., \& Pierce, G. (1987). A brief measure of social support: Practical and theoretical implications. Journal of Social and Personal Relationships, 4, 497-510. doi:10.1177/0265407587044007

Soderstrom, M., Dolbier, C., Leiferman, J., \& Steinhardt, M. (2000). The relationship of hardiness, coping strategies, and perceived stress to symptoms of illness. Journal of Behavioral Medicine, 23, 311-328. doi:10.1023/A:1005514310142

Stok, A., Harvey, D., \& Reddihough, D. (2006). Perceived stress, perceived social support, and wellbeing among mothers of school-aged children with cerebral palsy. Journal of Intellectual and Developmental Disability, 31, 53-57. doi:10.1080/13668250600561929

Tanaka, M., Fukuda, S., Mizuno, K., Kuratsune, H., \& Watanabe, Y. (2009). Stress and coping styles are associated with severe fatigue in medical students. Behavioral Medicine, 35, 87-92.

Thoits, P. (2001). Stress, coping, and social support processes: Where 
are we? What next? In W. Cockerham and M. Glasser (Eds.), Readings in Medical Sociology (2nd ed.), (pp. 55-87). New Jersey: Prentice Hall.

Treharne, G., Lyons, A., \& Tupling, R. (2001). The effects of optimism, pessimism, social support, and mood on the lagged relationship between daily stress and symptoms. Current Research in Social Psychology, 7, 60-81.

Watson, D., Clark, L., \& Tellegen, A. (1988). Development and validation of brief measures of positive and negative affect: The PANAS scales. Journal of Personality and Social Psychology, 54, 1063- 1070. doi:10.1037/0022-3514.54.6.1063

Watson, D., \& Pennebaker, J. (1989). Health complaints, stress, and distress: Exploring the central role of negative affectivity. Psychological review, 96, 234-254. doi:10.1037/0033-295X.96.2.234

Wilks, S., \& Croom, B. (2008). Perceived stress and resilience in Alzheimer's disease caregivers: Testing moderation and mediation models of social support. Aging \& Mental Health, 12, 357-365. doi:10.1080/13607860801933323

Zaleski, E., Levey-Thors, C., \& Schiaffino, K. (1998). Coping mechanisms, stress, social support, and health problems in college students. Applied Developmental Science, 2, 127-137. doi: $10.1207 / \mathrm{s} 1532480 \mathrm{xads} 02032$ 